\title{
Analyze the Usage of Social Media and Its Effects on Tertiary Level Students' Social Life
}

\section{SAJJAT HOSSAIN*, MD. NAZRUL ISLAM and MD. TABIUR RAHMAN PRODHAN}

Department of Mass Communication and Journalism Begum Rokeya University, Rangpur, Bangladesh.

\begin{abstract}
Social media (SM) are the fundamental component of the tertiary-level students' daily life, but it's a major concern that the usage of social media has various effects on the students' social life. The goal of the research was to examine the usage of SM and its effects on the students' social life at the tertiary level. The hypothesis of this study was to identify the association between the daily checking frequencies of SM and the effects of SM on tertiary level students' social, academic and personal life. To meet the study purpose, researchers employed quantitative survey methods and conducted a questionnaire-based face to face survey among 126 ( 67 male and 59 female) respondents, selected by the techniques of simple random sampling, the ages of the respondents were between 18 to 26 and studied at two tertiary level institutes in Rangpur city, the northern part of Bangladesh, which was selected purposively. From the participants, $94.44 \%$ had an account on SM. The popular SM was Facebook (90.48\%). Most of the respondents' were $(80.95 \%)$ used SM for entertainment. $62.7 \%$ of the students spent 1 to 4 hours in a day for SM usage. The using time is continuously increased among $77.78 \%$ of respondents while they start using SM. For measuring the SM Usage Effects (SMUE), researchers use 5 points Likert scale and use 10 statements where they found that seven (SMUE2, SMUE4, SMUE6, SMUE7, SMUE8, SMUE9, and SMUE10) have high effect, two (SMUE3 and SMUE5) have moderate effect, and only one (SMUE1) item has a low effect among the students. Researchers investigate the association with the participants' daily check SM and SMUE items, and 5 Pattern of SM Using (PSMU) items, all of the items were positive correlation and significant at $p<0.001$ level. Future studies should consider both quantitative and qualitative approaches to measure the impact of tertiary level students' social life and also to investigate the extent of addiction of SM users.
\end{abstract}

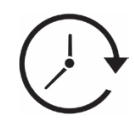

\section{Article History}

Received: 19 August 2020 Accepted: 14 September 2020

\section{Keywords}

Bangladesh;

Effects of SM Usage; Rangpur;

Social Media Usage;

Social Life;

Tertiary-Level Students.

CONTACT Md. Sajjat Hossain sajjathossainbrur@gmail.com 9 Department of Mass Communication and Journalism Begum Rokeya University, Rangpur-5404, Bangladesh.

\section{(c) (i)}

(C) 2020 The Author(s). Published by Enviro Research Publishers.

This is an Open Access article licensed under a Creative Commons license: Attribution 4.0 International (CC-BY).

Doi: http://dx.doi.org/10.12944/CRJSSH.3.2.03 


\section{Introduction}

In the present innovative world, social media (SM) is the new reality of human life. Easy access to the Internet around the globe has made SM a significant and most popular media of information and communication. SM sites have the ability to eliminate geographical separation for communication that endures between individuals (Gutzmann, 2018). At present, 65+ social media sites operate their activity in the world. Some of them are Facebook, Twitter, YouTube, Linkedln, WhatsApp, Viber, IMO, Google+, and so forth (Jamie, 2019). Social media users have expanded significantly in the world. Smith (2019) composes content in the brand watch blog about 126 Amazing Social Media Statistics and Facts, where he was indicated that the worldwide population is 7.7 billion. From whom 4.4 billion people use the internet. People who use the internet, among them 3.49 billion are deeply involved in social media use. This was 3.14 billion in 2018 ("Number of social network users," 2020). The scenario is no different in Bangladesh. In 2019, 34 million people in Bangladesh were using social media ("Digital 2019 Global Digital Yearbook," 2019), while in 2018, it was 30 million ("2018 Digital Yearbook," 2018). SM provides a new form of communication among family members, friends, acquaintances, classmates, etc. It has changed all aspects of people's lives. The most visible change was observed in the young generation, especially tertiary-level students. Tertiary-level students used social media for many purposes, one of them is learning. Alfaris et al., (2018) showed that 83.5 percent of students used YouTube, 35.5 percent used WhatsApp and 35.3 percent used Twitter to learn, and that 95.8 percent, 88.3 percent, 85.5 percent, and 40 percent used SM to entertain, up-to-date with news, socialize, and academic studies severally. Another study by Javed and Bhatti (2015) observed a large university student in Pakistan, where they found that the majority of the students frequently used SM sites to get information, keep in touch with friends, Connect with people they've missed contact with, for entertainment and learning. Jahan and Ahmed (2012) lead a study at a university in Bangladesh, where they investigate the students' tendency to engage with the SM sites regarding course related operations with a scale of seven- point. They noticed students were use SM sites for contact or connect with others, just behind watching or seen the class/course time, joining course, accessing the notes of the courses, and also some others materials. They also mention that students use SM sites for joining online discussion where only students are included. A similar study of Johnston et al., (2013) stated that $55 \%$ of their respondents' usage Facebook for contact with others to the class work questions and $47 \%$ for discussing class work. Students spend their time using social media this can affect their social and academic life. Many previous studies found the effects of SM usage on students' social life. Akbiyik (2013) showed that the effects of social networking on undergraduate students' social life. The study was a qualitative case study, where researcher was chosen Facebook as the case because of its popularity among college students. The findings revealed that almost all of the respondents agreed on the effects of Facebook on their social lives. Another study conducted by Akakandelwa and Walubita (2017) indicated that 70.9 percent of their respondents either frequently or sometimes spend more time on SM, 75.8 percent often or sometimes checking SM sites before doing anything else; 59.3 percent sometimes or often felt their academic productivity suffered as a result of using SM; $62.3 \%$ Often or always attempted to minimize the time spent on SM but failed; $76.2 \%$ had often or sometimes found themselves saying 'only a few more minutes' while using SM; $60.8 \%$ had often or sometimes heard other people commenting negatively about their use of SM, and $55.9 \%$ had often or sometimes felt stressed out because of their use of SM. They also stated that 42 percent of their respondents considered themselves to be negatively affected by SM; 32 percent identified themselves as often negatively affected by SM; 21 percent ranked themselves as sometimes negatively affected by SM, and only 5 percent rated themselves as never negatively affected by the use of SM in their social life.

Social media also the effect of students' academic life, but who spend their time wisely they would be able to improve their academic performance (Kulidtod and Pasagui 2017, Sutherland et al., 2018). If anyone failed to regulate their usage, then sometimes they could be addicted and harm their studies, and they can be distracted from their study (Okyeadie et al., 2016). 


\section{Hypothesis of the Study}

$\mathrm{H1}$ : There is an association between the daily checking frequencies of SM and the effects of SM on tertiary level students' social, academic, and personal life.

\section{Methods \\ Study Procedure}

The purposes of the study are to identify the pattern of SM usage among the study participants and to investigate the effects of SM usage among the respondents. To meet the study purposes the quantitative survey method was employed. Researchers select 126 (67 male and 59 female) respondents by the techniques of simple random sampling. Researchers developed the research questionnaire for this study. Self-administrated printed questionnaires were provided to the participants and said to them carefully read and complete the questionnaire. Respondents were Tertiary-level students from two institutes, 74 (58.73\%) were Begum Rokeya University, Rangpur (BRUR), and 52 (41.27\%) were Carmichael College, Rangpur (CCR). Researchers purposively select these two institutes to keep in mind that these are larger than other institutions in Rangpur. Several districts of the country's student studied at BRUR, and almost all the districts of Rangpur division student studied at CCR. It was during 3 to 25 December, 2019 when the researchers' collect the research data. The respondents were $99(78.57 \%)$ undergraduate and $27(21.43 \%)$ postgraduate programs students. Undergraduate participants were four academic year students. The respondents' ages ranged between 18 and 26 . Most of them 115 (91.27\%) were unmarried and $11(8.73 \%)$ were married. Among the 30 students who had social media accounts, pretesting was performed. The final survey incorporated the pretest community responses. Researchers used 5 points Likert scale for measure the effects, ranging from strongly disagree to strongly agree. Respondents give responses in the study without any pay and they were aware of the goal of the study. The present research was carried out in Rangpur, the northern part of Bangladesh, on a sample of tertiary level students' from two institutions (only 126 participants). Therefore these results cannot be generalized to all tertiary level students in Bangladesh. Researchers use only a quantitative approach for measuring the effect, but in-depth qualitative analysis requires analyzing the effect.

\section{Data Analysis}

The frequency distribution of the Microsoft Excel (Ms.) system was employed for analyzing the items relating to SM usage. The Statistical Package for the Social Science (SPSS) v.23.0 was used for the analysis of the Principal Component Analysis (PCA). $\mathrm{PCA}$ has become one of the reduction strategies for sample data that indicates any potential of variables and their degree of significance in a huge sample size. The PCA findings were also used to figure out how many items should be retained and how many elements should be retained for each of those items. Descriptive statistics (e.g., Mean, Standard Deviation, Variance, Skewness, Kurtosis, and Standard error, Median, Mode, Minimum, and Maximum) were employed to summarize the social media usage effect (SMUE). Pearson's correlation coefficient was applied for identifying the relationships among effects items and also to find out the relationship of effects items and five SM using pattern (SMUP) items with the users' daily checking frequencies of social media. Researchers use daily checking frequency of social media as an independent variable (IV) because it changed the state of dependent variables (DVs) items. We used the effects of using social media and five using pattern items as dependent variables (DVs) in (Table 5) for measuring the correlation between IV and DVs.

\section{Result}

Social Media Usage among the Study Participants Almost all $(94.44 \%)$ of the participants had an SM account, the rest of the others (5.56\%), had not an account of SM, but they also using SM like YouTube. Facebook was the most used SM site $(90.48 \%)$, followed by YouTube (81.75\%), IMO (44.45\%), WhatsApp (27.78\%), and Instagram (18.25\%). Twitter (13.49\%) was the least preferable SM site. $8.73 \%$ of students have all social media platform account, and they use these social media sites. The majority of $80.95 \%$ of the respondents used SM for entertainment, followed by $69.05 \%$ said they use to keep in touch with a friend, $68.25 \%$ states that they searching for news and information, $31.75 \%$ search their familiar friend, $34.92 \%$ use these for academic 
purpose, $24.60 \%$ used for sharing information and $9.52 \%$ said they use to find a new friend or meet new people (Table 1).

Most $(62.7 \%)$ of the students, spent 1 to 4 hours per day on SM and $26.19 \%$ spent on SM for more than
4 hours. A limited number $(n=14,11.11 \%)$ of the students spent less than 30 minutes and 30 minutes to 1 hour. Seventy-six (60.31\%) students checked their SM sites four times and more than four times in a day. $17.46 \%$ checked 2 times and rests of others checked in one, and three times (Table 1).

Table 1: Pattern of SM usage among respondents

\begin{tabular}{|c|c|c|c|}
\hline Statement & Categories & Frequency & Percentage \\
\hline \multirow[t]{2}{*}{ Have an account of SM } & Yes & 119 & 94.44 \\
\hline & No & 7 & 5.56 \\
\hline \multirow[t]{7}{*}{ SM that are used by respondents } & Facebook & 114 & 90.48 \\
\hline & YouTube & 103 & 81.75 \\
\hline & Twitter & 17 & 13.49 \\
\hline & Instagram & 23 & 18.25 \\
\hline & WhatsApp & 35 & 27.78 \\
\hline & $\mathrm{IMO}$ & 56 & 44.45 \\
\hline & All & 11 & 8.73 \\
\hline \multirow[t]{8}{*}{ Reasons for SM usage among students } & To keep in touch with friend & 87 & 69.05 \\
\hline & Find new friend & 12 & 9.52 \\
\hline & Search familiar friend & 40 & 31.75 \\
\hline & Sharing information & 31 & 24.60 \\
\hline & Entertainment & 102 & 80.95 \\
\hline & Academic work & 44 & 34.92 \\
\hline & News and information & 86 & 68.25 \\
\hline & Others & 27 & 21.43 \\
\hline \multirow[t]{5}{*}{ Time spent on SM every day } & Less than 30 minute & 5 & 3.97 \\
\hline & 30 minute to 1 hour & 9 & 7.14 \\
\hline & 1 to 2 hours & 17 & 13.49 \\
\hline & 2 to 4 hours & 62 & 49.21 \\
\hline & More than 4 hours & 33 & 26.19 \\
\hline \multirow[t]{5}{*}{ Daily checking frequency of SM } & One time & 16 & 12.70 \\
\hline & 2 times & 22 & 17.46 \\
\hline & 3 times & 12 & 9.52 \\
\hline & 4 times & 15 & 11.90 \\
\hline & More than 4 times & 61 & 48.41 \\
\hline \multirow{2}{*}{$\begin{array}{l}\text { Personal information (phone number, age, } \\
\text { marital status, family member, relationship } \\
\text { status) share on SM profile }\end{array}$} & Yes & 91 & 72.22 \\
\hline & No & 35 & 27.78 \\
\hline \multirow{5}{*}{$\begin{array}{l}\text { Usage SM before the time of sleeping } \\
\text { in the bed }\end{array}$} & Always & 82 & 65.08 \\
\hline & Sometimes & 14 & 11.11 \\
\hline & Very low & 8 & 6.35 \\
\hline & Never & 13 & 10.32 \\
\hline & Not at all & 9 & 7.14 \\
\hline \multirow[t]{4}{*}{ Usage SM after waking in the morning } & Always & 78 & 61.90 \\
\hline & sometimes & 17 & 13.49 \\
\hline & Very low & 6 & 4.76 \\
\hline & Never & 12 & 9.52 \\
\hline
\end{tabular}


Chatting with unknown person

Aware about share personal information by messaging

Doing video call by using SM

Difficult to sleep without using SM

Usage SM while walking on road

Usage SM during class lecture

Comparison of SM usage while starting

$\begin{array}{ccc}\text { Not at all } & 13 & 10.32 \\ \text { Always } & 21 & 16.67 \\ \text { Never } & 94 & 74.60 \\ \text { sometimes } & 11 & 8.73 \\ \text { Yes } & 87 & 69.05 \\ \text { No } & 39 & 30.95 \\ \text { Yes } & 43 & 34.13 \\ \text { No } & 83 & 65.87 \\ \text { Yes } & 14 & 11.11 \\ \text { No } & 112 & 88.89 \\ \text { Always } & 7 & 5.56 \\ \text { sometimes } & 24 & 19.05 \\ \text { Very low } & 15 & 11.90 \\ \text { Never } & 52 & 41.27 \\ \text { Not at all } & 28 & 22.22 \\ \text { Always } & 21 & 16.67 \\ \text { sometimes } & 27 & 21.43 \\ \text { Very low } & 4 & 3.17 \\ \text { Never } & 31 & 24.60 \\ \text { Not at all } & 43 & 34.12 \\ \text { Increased } & 98 & 77.78 \\ \text { About the same } & 17 & 13.49 \\ \text { Decreased } & 11 & 8.73\end{array}$

the same, and decreased, respectively. $5.56 \%$ of students used social media while walking on the road (Table 1).

\section{Social Media Effect Analysis}

In this study, participants' effect on social media use scores assessed with a Likert scale of 5 points. Respondents invited to address how much they comply with the social media effect statements or deny them. A total of 10 statements were set in the questionnaire to get the reply to how much effect they have for the usage of social media.

While strongly agreeing with the statement, they carry 5 points and strongly disagree with carrying 1 point. However, for more investigation, ten statements retained whose PCA allowed two factors with eigenvalues values greater than 1.0, explaining $89.7 \%$ of the overall variance. The findings are listed in (Table 2). The first factor comprised 6 items among the total 10, had an eigenvalue of 7.967 , and explained 79.7 percent of the variance. Among the 6 items, one was cross-loaded with the second factor. The second factor consisted of 5 variables; with an eigen value value of 1.007 , and 10.1 percent of the 
overall variance was described. Such elements were utilized to calculate the correlation matrix, descriptive statistics, and correlation between the independent variable and dependent variables.

Table 2: Factor analysis of effect for social media usage items of the respondents

\begin{tabular}{|c|c|c|c|c|c|c|}
\hline \multirow[t]{2}{*}{ Statement } & \multirow[t]{2}{*}{ Mean } & \multirow{2}{*}{$\begin{array}{c}\text { Std. } \\
\text { deviation }\end{array}$} & \multirow[t]{2}{*}{ Skewness } & \multirow[t]{2}{*}{ Kurtosis } & \multicolumn{2}{|c|}{ Factor } \\
\hline & & & & & 1 & 2 \\
\hline $\begin{array}{l}\text { Negative impact on relation with } \\
\text { friends and family (SMUE1) }\end{array}$ & 2.32 & 1.41 & 0.837 & -0.660 & & 0.840 \\
\hline Time waste for using (SMUE2) & 3.91 & 1.39 & -0.982 & -0.364 & 0.941 & \\
\hline $\begin{array}{l}\text { Negative impact on academic } \\
\text { performance (SMUE3) }\end{array}$ & 2.66 & 1.62 & 0.420 & -1.461 & & 0.758 \\
\hline Family complains about use (SMUE4) & 3.91 & 1.50 & 0.468 & -1.261 & & 0.709 \\
\hline $\begin{array}{l}\text { Finding life boring without social media } \\
\text { use within a day (SMUE5) }\end{array}$ & 3.48 & 1.54 & -0.466 & -1.297 & & \\
\hline \multirow{2}{*}{$\begin{array}{l}\text { Improve communication level (SMUE6) } \\
\text { social media reducing the time, effort and } \\
\text { money to access academic information } \\
\text { (SMUE7) }\end{array}$} & 3.98 & 1.43 & -1.120 & -0.283 & 1.054 & \\
\hline & 3.74 & 1.47 & -0.655 & -1.124 & 0.925 & \\
\hline $\begin{array}{l}\text { Break concentration from study for usage } \\
\text { social media during the time of study } \\
\text { (SMUE8) }\end{array}$ & 3.91 & 1.02 & -0.910 & -0.845 & 0.559 & 0.415 \\
\hline \multirow{2}{*}{$\begin{array}{l}\text { Effect on mental health (SMUE9) } \\
\text { Exchange important document for } \\
\text { the subject (SMUE10) }\end{array}$} & 3.92 & 1.09 & -1.000 & 0.375 & 0.992 & \\
\hline & 3.64 & 1.47 & -0.487 & -1.313 & & 1.050 \\
\hline \multicolumn{5}{|c|}{ Initial Eigenvalues } & 7.967 & 1.007 \\
\hline \multicolumn{5}{|c|}{$\%$ of Variance } & 79.7 & 10.1 \\
\hline \multicolumn{5}{|c|}{ Cumulative \% } & 79.7 & 89.7 \\
\hline
\end{tabular}

\section{Correlation Matrix}

After completing the PCA, the retained statements were used for analyze the Pearson moment correlation to identify the correlation among the items. The result introduced in (Table 3).

Table 3 depicts that the range of correlation between the variables (SMUE1, SMUE2, SMUE3, SMUE4, SMUE5, SMUE6, SMUE7, SMUE8, SMUE9, and SMUE10) is 0.25 to 0.97 which indicates weak to strong relationship between the variables. The correlation between SMUE3 and SMUE4 of the participants is the highest $(r=0.971)$ among all variables and on the other hand, there is the lowest value $(r=0.254)$ between SMUE8 and SMUE9. All of the variables are positive significant association among one another.

\section{Effect of Social Media Usage}

Table 4 presents a scenario of the participants' effect on SM usage. The data obtained using a '5' point Likert scale for calculating the effect of SM use where the scale is between 1 (Strongly Disagree) and 5 (Strongly Agree). The result indicates that the mean value of social media use effect among students ranged from 3.98 to 2.32 with a standard deviation ranging from 1.02 to 1.62 , to assess the effect of social media use, researchers identified low, medium, high and very high effect rates. Mean below and 2.5 represent low effect, mean between 2.6 to 3.49 represents medium effects, mean between 3.5 to 4 represents high effect, and mean above 4 represents very high effect. 
Table 3: Correlation matrixes of different items collected to analyze the effect for social media usage of the respondents

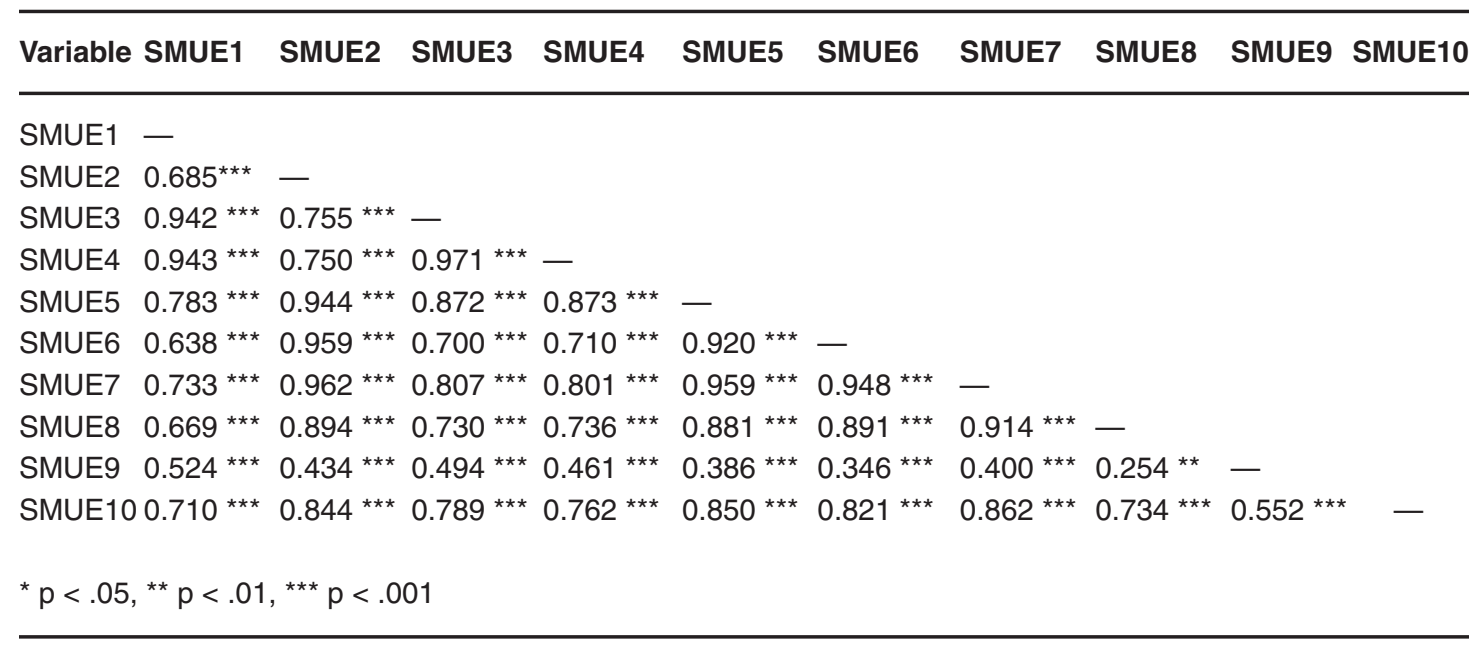

Note: ${ }^{* *}$ correlation is significant at the 0.001 level

${ }^{\star *}$ correlation is significant at the 0.01 level

*correlation is significant at the 0.05 level

Table 4: Descriptive statistics of effect for the usage of SM of the respondents

\begin{tabular}{|c|c|c|c|c|c|c|c|c|}
\hline Statement & Mean & $\begin{array}{c}\text { Std. } \\
\text { deviatio }\end{array}$ & Variance & $\begin{array}{l}\text { Std. } \\
\text { error }\end{array}$ & Median & Mode & Min & Max \\
\hline $\begin{array}{l}\text { Negative impact on relation with } \\
\text { friends and family (SMUE1) }\end{array}$ & 2.32 & 1.41 & 1.98 & 0.13 & 2 & 1 & 1 & 5 \\
\hline Time waste for using (SMUE2) & 3.91 & 1.39 & 1.94 & 0.12 & 5 & 5 & 1 & 5 \\
\hline $\begin{array}{l}\text { Negative impact on academic } \\
\text { performance (SMUE3) }\end{array}$ & 2.66 & 1.62 & 2.61 & 0.14 & 2 & 1 & 1 & 5 \\
\hline Family complains about use (SMUE4) & 3.91 & 1.50 & 2.26 & 0.13 & 5 & 5 & 1 & 5 \\
\hline $\begin{array}{l}\text { Finding life boring without social media } \\
\text { use within a day (SMUE5) }\end{array}$ & 3.48 & 1.54 & 2.36 & 0.14 & 4 & 5 & 1 & 5 \\
\hline Improve communication levels (SMUE6) & 3.98 & 1.43 & 2.05 & 0.13 & 5 & 5 & 1 & 5 \\
\hline $\begin{array}{l}\text { social media reducing the time, effort } \\
\text { and money to access academic } \\
\text { information (SMUE7) }\end{array}$ & 3.74 & 1.47 & 2.16 & 0.13 & 4.5 & 5 & 1 & 5 \\
\hline $\begin{array}{l}\text { Break concentration from study for } \\
\text { usage social media during the time } \\
\text { of study (SMUE8) }\end{array}$ & 3.87 & 1.02 & 1.03 & 0.09 & 4 & 4 & 1 & 5 \\
\hline Effect on mental health (SMUE9) & 3.92 & 1.09 & 1.19 & 0.09 & 4 & 4 & 1 & 5 \\
\hline $\begin{array}{l}\text { Easy exchange important document } \\
\text { for the subject (SMUE10) }\end{array}$ & 3.64 & 1.47 & 2.15 & 0.13 & 4 & 5 & 1 & 5 \\
\hline
\end{tabular}

From the above table 4 , the mean score of all the statements revealed that seven items have a high effect on students. For example, 'improve communication levels (SMUE6)' have the highest mean score $(M=3.98, S D=1.43)$ followed by 'effect on mental health (SMUE9)', it takes the mean score 
and standard deviation ( $\mathrm{M}=3.92, \mathrm{SD}=1.09)$. 'Time waste for using (SMUE2)' and 'family complains about using (SMUE4)' both of the items take the same mean sore $(M=3.91, S D=1.39)$ and $(M=3.91$, $\mathrm{SD}=1.50)$, respectively. 'Break concentration from the study for using social media during the time of the study (SMUE8)' and 'social media reducing the time, effort and money to access academic information (SMUE7)' and 'easy exchange important document for the subject (SMUE10)' respectively take the following step. The mean score of these items is $(M=3.87, S D=1.02),(M=3.74, S D=1.47)$ and $(\mathrm{M}=3.64, \mathrm{SD}=1.47)$ respectively. Two items have a moderate effect on the respondents. These two items are 'finding life boring without social media use within a day (SMUE5)' and 'negative impact on academic performance (SMUE3)'. The mean score of these items is $(M=3.48, S D=1.54)$ and $(M=2.66$, $S D=1.62$ ) respectively. Only one item has a low effect. This item is a 'negative impact on the relation with friends and family (SMUE1)' and the mean score is $(\mathrm{M}=2.32, \mathrm{SD}=1.41)$.

Table 5: Correlation between independent variable and dependent variables

\begin{tabular}{|c|c|c|}
\hline $\begin{array}{l}\text { Independent } \\
\text { variable }\end{array}$ & Dependent variables & $\begin{array}{l}\text { Pearson } \\
\text { moment } \\
\text { correlation }\end{array}$ \\
\hline \multirow{15}{*}{$\begin{array}{l}\text { Daily checking } \\
\text { frequency of SM }\end{array}$} & Negative impact on relation with friends and family (SMUE1) & $0.710 * * *$ \\
\hline & Negative impact on academic performance (SMUE2) & $0.789 * * *$ \\
\hline & Family complains about use (SMUE3) & $0.762 * * *$ \\
\hline & Finding life boring without social media use within a day (SMUE4) & $0.850 * * \star$ \\
\hline & Improve communication level (SMUE5) & $0.821^{* * *}$ \\
\hline & $\begin{array}{l}\text { social media reducing the time, effort and money to access } \\
\text { academic information (SMUE6) }\end{array}$ & $0.862^{* \star *}$ \\
\hline & $\begin{array}{l}\text { Break concentration from study for usage social media during } \\
\text { the time of study (SMUE7) }\end{array}$ & $0.734^{* \star *}$ \\
\hline & Effect on mental health (SMUE8) & $0.552^{* * *}$ \\
\hline & Exchange important document for the subject (SMUE9) & $0.921^{\star \star \star}$ \\
\hline & Time waste for using (SMUE10) & $0.844^{* * *}$ \\
\hline & Time spent on SM every day (PSMU1) & $0.552 * * *$ \\
\hline & Usage SM before the time of sleeping in the bed (PSMU2) & $0.810 * * *$ \\
\hline & Usage SM after waking in the morning (PSMU3) & $0.827^{* * *}$ \\
\hline & Usage SM while walking on road (PSMU4) & $0.768 * * \star$ \\
\hline & Usage SM during class lecture (PSMU5) & $0.791^{* * *}$ \\
\hline
\end{tabular}

${ }^{*} p<.05,{ }^{* *} p<.01,{ }^{* * *} p<.001$

Correlation between the Dependent Variable and Selected Independent Variables

In this section, users' daily checking frequency was used as an independent variable. The dependent variables included an effect on the usage of social media items and five using pattern items. The test of Pearson moment correlation was adopted to analyze the association between the independent variable (IV) and dependent variables (DV). To test the hypothesis concerning relationship between the independent and dependent variables Pearson's $r$ was computed. $P<0.01, p<0.05$, and $p<0.001$ level of probability used as the basis for responding to the research hypothesis, A strong positive association with the IV and DVs were identified where the value of ' $r$ ' was significant at $P<0.01, P<0.05$, and $P<0.001$. A Summary of the fifteen correlations, present in (Table 5)

The Pearson coefficient correlation test represented that negative impact on the relation with family (SMUE1), negative impact on academic performance 
(SMUE2), family complains about the use (SMUE3), finding life boring without social media use within a day (SMUE4), improve communication level (SMUE5), social media reducing the time, effort and money to access academic information (SMUE6), break concentration from the study for using social media during the time of the study (SMUE7), the effect on mental health (SMUE8), exchange important document for the subject (SMUE9), time waste for using (SMUE10), Time spent on SM every day (PSMU1), using SM before the time of sleeping in the bed (PSMU2) and using SM after waking in the morning (PSMU3), usage SM while walking on the road (PSMU4) and usage SM during class lecture (PSMU5) were positive and significant correlation with the users' daily checking frequency (Table 5).

Table 5 depicts that among the effect items 'exchange important document for the subject (SMUE9)' has the positive highest significance bearing the r-value 0.921 which was significant at $p<0.001$ level of probability. Following the 'social media reducing the time, effort and money to access academic information (SMUE6)' has the second-highest positive significance with an r-value of 0.862 which is also significant at $p<0.001$ level of probability. Finding life boring without social media use within a day (SMUE4), time waste for using (SMUE10), improve communication level (SMUE5), negative impact on academic performance (SMUE2), family complains about the use (SMUE3), negative impact on the relation with friends and family (SMUE1), break concentration from the study for using social media during the time of the study (SMUE7), and effect on mental health (SMUE8) were gain significant $r$ value consecutively $0.850,0.844$, $0.821,0.789,0.762,0.710,0.734$ and 0.552 (Table 5). From the using pattern items 'usage SM after waking in the morning (PSMU3)' has the highest positive significant correlation with the r-value 0.827 which was significant at $p<0.001$ level of probability. Following the 'usage SM before the time of sleeping in the bed (PSMU2)' has the second-highest positive significance with an r-value of 0.810 which is also significant at $p<0.001$ level of probability. Usage SM during class lecture (PSMU5), usage SM while walking on the road (PSMU4), time waste for using (PSMU1) graded the r-value 0.791, 0.768, and 0.552 (Table 5).

\section{Discussion}

Using Social Media has been one of the people's core daily practices. This research examines social media usage and its effect on the respondents. The current study findings revealed that more than $90 \%$ of the tertiary level students had SM account. In a previous study by Al-Menayes (2015) stated that $99 \%$ of his sample told him they had social media account. From the analysis, researchers find out that the most preferred or used social media is Facebook. Many previous studies like Aljasir et al. (2014), Celik \& Karaaslan (2014), Jahan \& Ahmed (2012), Javed \& Bhatti (2015), and Prodhan et al., (2020) further confirm that Facebook is the most favorite social media platform. There are several reasons for tertiary level students' usage of social media. Our finding demonstrates that the majority of $80.95 \%$ of the respondents used social media for entertainment, followed by $69.05 \%$ said they use social media to keep in touch with a friend, $68.25 \%$ states that they searching news and information and $34.92 \%$ use these for academic purpose. In a study conducted by Otu (2015) where he found that majority of the respondents $(29 \%)$ use their social media account for entertainment, followed by $22.3 \%$ who use social media for creating media content and sharing opinions while $20.3 \%$ stated they use SM to meet new people. Other researcher finding uncovered that students used SM for passing time (Weber 2012) for entertainment (Quan-Haase and Young 2010; Mehmood and Taswir 2013) and maintain the relationship with others (Kietzmenn et al., 2011). The present study result revealed that most $(62.7 \%)$ of the respondents spend 1 to 4 hours per day in social media than the previous study Alfaris et al., (2018) showed that $55 \%$ of their respondents used social media in the range of 1 to 4 hours. In our study, we note that almost $(60.31 \%)$ students checked SM 4 times and also more than four times in a day, while Alfaris et al. (2018) mention that $76.7 \%$ of the respondents check daily basis in the same range. This study found that $72.22 \%$ of respondents share their personal information in their social media profiles. All most all the users (82.54\%) using social media before the time of sleeping in the bed. $80.15 \%$ usage after waking in the morning. Around $75 \%$ don't chat with unknown persons through the usage of social media. Researchers noted that most of the respondents are aware of 
share their personal information through social media messaging. $34.13 \%$ conducted a video call by using social media. $36.51 \%$ used social media while walking on the road. $41.27 \%$ used SM during the class lecture. A large number $(77.78 \%)$ of the students said their using time increased while they start to use social media.

Researchers adopted ten statements to investigate the SMUE. To measure the effect we use a Likert scale of 5 points. The range of scale was 1 to 5 that means Strongly Disagree to Strongly Agree. The result revealed that mean value of the SMUE among students ranged from 3.98 to 2.32 with standard deviation ranging from 1.02 to 1.62 , to assess the SMUE researchers identified as low, medium, high, and very high impact.

The following descriptor was adopted within all the subscales on the study that used the same frequency scale of 1 (strongly disagree) to 5 (strongly agree). Mean below 2.5 represent low effect, mean between 2.6 to 3.49 represents medium effect, and between mean 3.5 to 4 represents high effect and mean above 4 represents a very high effect. Alghamdi and Plunkett (2018) used an almost similar type of scale to measure the effect.

The mean score of the study mention that seven (SMUE2, SMUE4, SMUE6, SMUE7, SMUE8, SMUE9, and SMUE10) items have a high impact on students. Among them, three (SMUE6, SMUE7, and SMUE10) were a positive effects on the students. From the ten statements, two (SMUE3 and SMUE5) have a moderate effect on the respondents, and only one (SMUE1) has a low effect on the study participants.

The Pearson coefficient correlation test represented that among the 15 dependent variables, all were positively significant. Among these variables of the effect items 'exchange important document for the subject (SMUE9)' has the positive highest significance bearing the r-value 0.921. Following the 'social media reducing the time, effort, and money to access academic information (SMUE6)' has the second-highest positive significance with an r-value, of 0.862 these are significant at $p<0.001$ level of probability. From the using pattern items, 'using SM after waking in the morning (PSMU3)' has the highest positive significant correlation with the r-value 0.827 . Following the 'usage SM before the time of sleeping in the bed (PSMU2)' has the second-highest positive significance with an r-value of 0.810 these are also significant at $p<0.001$ level of probability.

\section{Conclusion}

The research showed the usage of SM and its effect on students' social life at the tertiary level. The study depict that the majority of the respondents had an account of social media. Students, who had not an account, he/she also used SM like YouTube. Facebook had become an influential social media. Users' least preferred SM was Twitter. Participants use SM mainly for entertainment; stay in contact with friends and family, as well as news, information, and academic purposes. Respondents spent time for frequently use SM. Students' usages of SM are increasing day by day. The usage of social media had an effect of the students' academic performance, friends and family relation, mental health, study concentration, generate boring life, improving communication level, easily exchange study document, and so on. Researchers found seven statements that have a high effect on the participants. Daily checking frequencies of SM with effects of SM and usage pattern of SM are found significant association. Though there have both positive and negative effects, so respondents' should need to be conscious of the excessive usage of SM sites. A combined approach is badly needed to raise awareness among tertiary level students concerning the effects of social media. Future studies should consider both quantitative and qualitative approaches to measure the effect of tertiary level students' social life and also investigate the extent of addiction of SM users.

\section{Acknowledgement}

Researchers give thanks to the respondents, who give their valuable responses in the study without any payment.

\section{Funding}

There is no funding to be disclosed.

\section{Conflict of interest}

The authors declare that they have no competing interests. 


\section{Reference}

1. 2018 Digital Yearbook. (2018, January 29). Retrieved September 3, 2020, from https:// www.slideshare.net/wearesocial/2018-digitalyearbook-86862930?from_action=save

2. Akakandelwa, A., \& Walubita, G. (2018). Students' social media use and its perceived impact on their social life: A case study of the University of Zambia. The International Journal of Multi-Disciplinary Research, 1-14. Retrieved 6 September, 2020 from http://dspace.unza.zm/bitstream/ handle/123456789/5247/Aka\%20\%26\%20 Walubita.pdf?sequence $=1$ \&isAllowed $=y$

3. Akbiyik, C. (2013). Effects of Social Networks on Social life of Undergraduate students. Middle Eastern \& African Journal of Educational Research, 4(6), 4-10. Retrieved 6 September, 2020 from https://pdfs.semanticscholar.org/6 535/877a198e5942880211caa827ff2dbbeb6 9c3.pdf

4. AIFaris, E., Irfan, F., Ponnamperuma, G., Jamal, A., Van der Vleuten, C., Al Maflehi, N., Al-Qeas, S., Alenezi, A., Alrowaished, M., Alsalman, R. and Ahmed, A.M. (2018). The pattern of social media use and its association with academic performance among medical students. Medical teacher, 40(sup1), pp.S77-S82. https://doi.org/ 10.1080/0142159X.2018.1465536

5. Alghamdi, A. A., \& Plunkett, M. (2018). Perceptions of Saudi Male and Female Postgraduate Students Regarding the Impact of Social Networking Sites and Apps on their Academic Life: A Study of Umm Al-Qura University-Makkah. International Journal of Emerging Technologies in Learning (iJET), 13(05), 19-40. https://doi.org/10.3991/ijet. v13i05.7981

6. Aljasir, S., Woodcock, A., \& Harrison, S. (2014). Usage of social network sites amongst Saudis: Why do Saudi university students have multiple Facebook accounts?. International Journal of Social Science and Humanity, 4(4), 293-297. DOI: 10.7763/IJSSH.2014.V4.366

7. Al-Menayes, J.J. (2015). Dimensions of social media addiction among university students in Kuwait. Psychology and Behavioral Sciences, 4(1), pp.23-28. doi: 10.11648/j.pbs.20150401.14
8. Çelik, A.K. and Karaaslan, A. (2014). Predictors of college students' willingness to use social network services. Campus-Wide Information Systems, Vol. 31 No. 5, pp. 304-318. https://doi. org/10.1108/CWIS-01-2014-0003

9. Digital 2019 Global Digital Yearbook. (2019, January 31). Retrieved September 3, 2020, from https://datareportal.com/reports/ digital-2019-global-digital yearbook?utm source=Reports\&utm_medium=PDF\&utm_ campaign=Digital_2019\&utm_content=Global_ Overview_Promo_Slide

10. Gutzmann, L. (2018). Utilization of Social Media in Strengthening Communication in Long Distance Relationships. Retrieved September 3, 2020, from https://sophia.stkate.edu/cgi/ viewcontent.cgi $?$ article $=1863 \&$ context $=\mathrm{msw}_{\text {_ }}$ papers

11. Jahan, I. and Ahmed, S.Z. (2012). Students' perceptions of academic use of social networking sites: a survey of university students in Bangladesh. Information Development, 28(3), pp.235-247. https://doi. org/10.1177/0266666911433191

12. Jamie. (2019). 65+ Social Networking Sites You Need to Know About. Retrieved July 21, 2020, from https://makeawebsitehub.com/ social-media-sites/

13. Javed, M.W. and Bhatti, R. (2015). Usage of social media by medical and dental students at Nishtar Medical College, Multan, Pakistan. Journal of Hospital Librarianship, 15(1), pp.5364. https://doi.org/10.1080/15323269.2015.9 82031

14. Johnston, K., Tanner, M., Lalla, N. and Kawalski, D. (2013). Social capital: the benefit of Facebook 'friends'. Behaviour \& Information Technology, 32(1), pp.24-36. https://doi.org/10.1080/01449 29X.2010.550063

15. Kietzmann, J. H., Hermkens, K., McCarthy, I. P., \& Silvestre, B. S. (2011). Social media? Get serious! Understanding the functional building blocks of social media. Business horizons, 54(3), 241-251. https://doi.org/10.1016/j. bushor.2011.01.005

16. Kulidtod, R.R.C. and Pasagui, N.N.S. (2017). Effects of social networking media to the 
academic performance of the students. In 2nd International Conference on Educational Management and Administration (CoEMA 2017). Atlantis Press. https://doi.org/10.2991/ coema-17.2017.11

17. Mehmood, S. and Taswir, T. (2013). The effects of social networking sites on the academic performance of students in college of applied sciences, Nizwa, Oman. International Journal of Arts and Commerce, 2(1), pp.111-125. Retrieved from https://ijac.org.uk/images/ frontImages/gallery/Vol.2_No._1/10.pdf

18. Number of social network users worldwide from 2017 to 2025 in billions. (2020). Retrieved July 23, 2020, from https://www.statista.com/ statistics/278414/number-of-worldwide-socialnetwork-users/

19. Okyeadie M., S., Nizam, D.I., Mensah, O.S. and Nizam, I. (2016). The impact of social media on students' academic. International Journal of Education, Learning \& Training (IJELT), 1(1), pp.14-21. DOI: 10.24924/ijelt/2016.11/ v1.iss $1 / 14.21$

20. Otu, A.A. (2015). Social media addiction among students of the University of Ghana (Doctoral dissertation, University of Ghana). Retrieved from http://ugspace.ug.edu.gh/ handle/123456789/21223

21. Prodhan, M.T.R., Islam, M.N. and Hossain, M.S. (2020) Exploring the knowledge of social media platforms among higher education institute students' of Rangpur, Bangladesh. Recent Research in Science and Technology, 12: 1-5. https://doi.org/10.25081/rrst.2020.12.6288

22. Quan-Haase, A. and Young, A.L. (2010). Uses and gratifications of social media: A comparison of Facebook and instant messaging. Bulletin of science, technology \& society, 30(5), pp.350-361. https://doi.org/10.1177/0270467610380009

23. Smith, K. (2019). 126 Amazing Social Media Statistics and Facts. Brandwatch. Retrieved July 22,2020, from https://www.brandwatch.com/ blog/amazing-social-media-statistics-and-facts/

24. Sutherland, K., Davis, C., Terton, U. and Visser, I. (2018). University student social media use and its influence on offline engagement in higher educational communities. Student Success, 9(2), pp.13-24. https://doi.org/10.5204/ssj. v9i2.400

25. Weber, A. S. (2012). Considerations for social network site (SNS) use in education [PDf]. China Hong Kong City: International Journal of Digital Information and Wireless Communications. 